\title{
Produção e nutrição do capim-Marandu submetido a doses de zinco no solo
}

\author{
José Marcos Garrido Beraldo \\ Renato de Mello Prado* \\ Juan Waldir Mendoza Cortez \\ Adilson José Rocha Mello \\ Carlos Alberto Kenji Taniguchi \\ Universidade Estadual Paulista \\ Via de Acesso Prof. Paulo Donato Castellane, s/n, CEP 14870-000, Jaboticabal - SP, Brasil \\ * Autor para correspondência \\ rmprado@fcav.unesp.br
}

Submetido em 01/06/2011

Aceito para publicação em 19/12/2011

\section{Resumo}

O objetivo do trabalho foi avaliar o efeito de doses de zinco no estado nutricional e na produção de massa seca do capim-Marandu. O experimento foi realizado em casa de vegetação, em vasos com capacidade para $4 \mathrm{dm}^{3}$ de solo. O solo utilizado foi classificado como Latossolo Vermelho distrófico. O delineamento experimental foi o inteiramente casualizado, com seis doses de zinco $\left(0 ; 15 ; 30 ; 60 ; 120\right.$ e $\left.240 \mathrm{mg}^{-\mathrm{dm}^{-3}}\right)$ e quatro repetições. Foram determinados: o número de folhas e de perfilhos por vaso, a altura, a massa seca e o teor de zinco na parte aérea das plantas. A avaliação foi realizada em dois períodos (cortes), com intervalo de 30 dias. Após o segundo corte, avaliaram-se a concentração de zinco no solo e a massa seca de raiz. A aplicação de zinco ao solo incrementou sua concentração no solo e a absorção pelo capim-Marandu, atingindo a máxima produção de massa seca com teor de zinco na parte aérea, de 140 e $181 \mathrm{mg} . \mathrm{kg}^{-1}$, no primeiro e segundo cortes, respectivamente. Não foi observada toxidez de zinco nas doses utilizadas.

Palavras-chave: Absorção de zinco; Brachiaria brizantha; Forrageira; Micronutriente; Nutrição de plantas

\section{Abstract}

Production and nutrition of Marandu grass fertilized with zinc. The goal of this work was to evaluate the effect of zinc on the nutritional status and dry matter production of Marandu grass. The experiment was conducted in a greenhouse with containers filled with $4 \mathrm{dm}^{3}$ of an Oxisol soil. The experimental essays included six different doses of zinc $\left(0 ; 15 ; 30 ; 60 ; 120\right.$ and $\left.240 \mathrm{mg} \mathrm{dm}^{-3}\right)$, with four repetitions. The study evaluated the number of tillers and leaves, plant height, dry mass of the shoot and root system and the concentration of zinc in the soil and leaves. The assessment was made during two different periods (cuts), with an interval of 30 days. After the second cut, the concentrations of $\mathrm{Zn}$ in the soil and root dry mass were determined. The application of zinc to the soil increased its concentration and absorption by the Marandu grass, which reached 140 and $181 \mathrm{mg} . \mathrm{kg}^{-1}$ (first and second cut, respectively) in the dry mass. The zinc doses used were not toxic to the plants.

Key words: Brachiaria brizantha; Forpapge; Micronutrients; Plant nutrtion; Zinc absorption 


\section{Introdução}

No Brasil, existe um predomínio de gramíneas forrageiras do gênero Brachiaria, sendo a principal fonte de alimento para a produção animal. O capim-Marandu (Brachiaria brizantha (Hochst ex A. Rich) Stapf. cv. Marandu) tem-se destacado pela alta produção de massa seca, boa adaptabilidade, facilidade de estabelecimento, persistência e bom valor nutritivo. Além disso, apresenta poucos problemas de doenças e possui boas taxas de crescimento durante a maior parte do ano, inclusive no período seco (COSTA et al., 2005).

Apesar da importância das forrageiras na produção de carne e leite, a maioria das pastagens de braquiária no Estado de São Paulo encontra-se em estado de degradação. As causas mais prováveis da degradação podem ser atribuídas ao esgotamento da fertilidade do solo e ao manejo inadequado, que interferem na nutrição das plantas e limitam sua produção (SOARES-FILHO et al., 1992).

O fornecimento de nutrientes e o balanço nutricional na planta assumem importância fundamental na formação e manutenção da forrageira. Dentre os micronutrientes, o zinco induz diminuição na produtividade das culturas, especialmente em gramíneas, em consequência da sua carência no solo (FAGERIA; BALIGAR, 1997). Esse micronutriente é importante por estar relacionado ao metabolismo de fenóis, à formação de amido e ao aumento no tamanho e multiplicação celular (MALAVOLTA et al., 1991), possibilitando o crescimento e o desenvolvimento da planta.

Estudos realizados com capim-Tanzânia cultivado em solução nutritiva indicam que o zinco incrementa a produção de massa seca (MANARIN, 2005). No entanto, em outras espécies, tal efeito não foi verificado como em capim-Colonião (WERNER et al., 1967) e Tifton 85 (PALMA, 1999). Alguns autores ressaltam que altas doses de zinco podem induzir toxicidade em forrageiras, como em capim-Tanzânia (HERNANDES et al., 2009) e capim-Xaraés (SANTOS et al., 2009). Assim, é importante conhecer a quantidade correta de cada micronutriente para o adequado desenvolvimento da planta.
O objetivo do trabalho foi avaliar o efeito de doses de zinco no estado nutricional e na produção de massa seca do capim-Marandu.

\section{Material e Métodos}

O experimento foi conduzido em casa de vegetação da Faculdade de Ciências Agrárias e Veterinária Unesp, Campus Jaboticabal, situada no município de Jaboticabal-SP, com coordenadas geográficas de $21^{\circ} 15^{\prime} \mathrm{S}$ de latitude e $48^{\circ} 18^{\prime} \mathrm{W}$ de longitude, e altitude de $575 \mathrm{~m}$.

O delineamento experimental utilizado foi o inteiramente ao acaso, com seis doses de zinco $(0 ; 15$; $30 ; 60 ; 120$ e $\left.240 \mathrm{mg} \mathrm{dm}^{-3}\right)$ e quatro repetições.

Cada unidade experimental foi constituída por vaso com capacidade de $4 \mathrm{dm}^{3}$, preenchido com $3 \mathrm{dm}^{3}$ de um Latossolo Vermelho distrófico (EMBRAPA, 2006).

O solo apresentava as seguintes propriedades químicas: $\mathrm{pH}$ em $\mathrm{CaCl}_{2}$ 0,01mol.L $\mathrm{L}^{-1}=4,2 ; \mathrm{P}$ resina $=$ 5mg.dm ${ }^{-3} ;$ M.O. $=17 \mathrm{~g} . \mathrm{dm}^{-3} ; \mathrm{K}^{+}=0,5 \mathrm{mmol}_{\mathrm{c}} \mathrm{dm}^{-3} ; \mathrm{Ca}^{2+}=$ $4 \mathrm{mmol}_{\mathrm{c}} \mathrm{dm}^{-3} ; \mathrm{Mg}^{2+}=2 \mathrm{mmol}_{\mathrm{c}} \mathrm{dm}^{-3} ; \mathrm{H}+\mathrm{Al}=58 \mathrm{mmol}_{\mathrm{c}} \mathrm{dm}^{-3}$; $\mathrm{SB}=6,5 \mathrm{mmol}_{\mathrm{c}} \mathrm{dm}^{-3} ; \mathrm{CTC}=64,5 \mathrm{mmol}_{\mathrm{c}} \mathrm{dm}^{-3} ; \mathrm{V}=10 \% \mathrm{e}$ $\mathrm{Zn}=0,4 \mathrm{mg} \cdot \mathrm{dm}^{-3}$, analisado conforme as metodologias descritas em Raij et al. (2001).

A aplicação de calcário $(\mathrm{CaO}=58,5 \% ; \mathrm{MgO}=9 \%$; $\mathrm{PN}=127 \%$ e PRNT $=125 \%$ ) foi realizada para elevar a saturação por bases a 70\% (RAIJ et al., 1996), seguido de um período de 60 dias de incubação.

Após o período de incubação, foi realizada a aplicação do zinco na forma de sulfato de zinco $\left(\mathrm{ZnSO}_{4} \cdot 7 \mathrm{H}_{2} \mathrm{O}\right)$, conforme os tratamentos. A adubação básica foi realizada de acordo com Bonfim et al. (2004), aplicando-se $200 ; 1,2 ; 0,8 ; 1,5 ; 3,5$ e $0,15 \mathrm{mg}$. $\mathrm{dm}^{-3}$ de $\mathrm{K}, \mathrm{Cu}, \mathrm{B}, \mathrm{Fe}, \mathrm{Mn}$ e Mo, respectivamente, utilizando os seguintes sais: $\mathrm{KCl}, \mathrm{CuSO}_{4} .5 \mathrm{H}_{2} \mathrm{O}, \mathrm{H}_{3} \mathrm{BO}_{3}$, $\mathrm{Fe}_{2}\left(\mathrm{SO}_{4}\right)_{2} \cdot 4 \mathrm{H}_{2} \mathrm{O}, \mathrm{MnCl}_{2} \cdot 6 \mathrm{H}_{2} \mathrm{O}$ e $\mathrm{NaMoO}_{4} \cdot 2 \mathrm{H}_{2} \mathrm{O}$. Aplicaram-se, ainda, 305mg. $\mathrm{dm}^{-3}$ de $\mathrm{P}$ na forma de superfosfato simples, conforme recomendação de Mesquita et al. (2004).

A semeadura do capim-Marandu foi realizada em bandejas contendo areia como substrato, e sete dias após sua emergência as mudas foram transplantadas para 
os vasos. Após 20 dias do transplantio, foi realizado o desbaste, de modo a deixar cinco plantas por vaso, e um corte de uniformização a cinco centímetros do solo.

Foram feitas três adubações nitrogenadas de $100 \mathrm{mg} \cdot \mathrm{dm}^{-3} \mathrm{de} \mathrm{N}$ na forma de ureia, sendo duas durante o primeiro ciclo de crescimento ( 9 e 42 dias após o transplantio) e a outra durante o segundo ciclo de crescimento (31 dias após o primeiro corte das plantas).

Durante o desenvolvimento do experimento, foi realizada a adição de água desionizada, visando a manter o solo próximo de $70 \%$ da capacidade de retenção de água.

Foram realizadas duas avaliações de crescimento, tendo como variáveis o número de folhas, de perfilhos e a altura das plantas (do colo da planta até a extremidade da folha de maior comprimento). A produção de massa seca da parte aérea foi avaliada, a partir do corte das plantas, a $10 \mathrm{~cm}$ do solo, sendo o primeiro corte aos 30 dias após o corte de uniformização, e o outro, 30 dias após o primeiro corte.

No segundo corte, os vasos foram desmontados para a coleta das raízes e de amostras de solo. No solo, foi determinada a concentração de zinco conforme metodologia descrita em Raij et al. (2001).

A parte aérea das plantas foi lavada na seguinte sequência: em água corrente, em solução de detergente neutro $1 \mathrm{~mL} . \mathrm{L}^{-1}$, em água desionizada, em solução de $\mathrm{HCl}$ $0,1 \mathrm{~mol}^{-\mathrm{L}^{-1}}$ e novamente em água desionizada por mais duas vezes e, por fim, secas em papel-toalha. O material vegetal foi seco em estufa com circulação forçada de ar até atingir peso constante, à temperatura de $65^{\circ}$ a $70^{\circ} \mathrm{C}$. Em seguida, a parte aérea foi moída para determinar o teor de zinco, conforme metodologia descrita por Bataglia et al. (1983).

O cálculo da eficiência agronômica (EA) foi realizado conforme metodologia proposta por Fageria e Barbosa Filho (2007). Indica a produção da massa seca da parte aérea do capim (soma dos dois cortes) por unidade de zinco aplicada, de acordo com a fórmula:

$\left.\mathrm{EA}\left(\mathrm{g} \mathrm{g}^{-1}\right)=\left(\mathrm{PMS}_{\text {com Zn }}-\mathrm{PMS}_{\text {sem Zn }}\right) / \mathrm{QZn}\right)$, em que: $\mathrm{PMS}_{\text {com Zn }}$ indica a massa seca da parte aérea nos vasos com zinco $(\mathrm{g})$; $\mathrm{PMS}_{\mathrm{sem} \mathrm{Zn}}$ indica a massa seca da parte aérea nos vasos sem zinco $(\mathrm{g})$, e QZn indica a quantidade de zinco aplicada $(\mathrm{g})$

Durante o desenvolvimento e ao longo do período experimental, as plantas foram monitoradas para verificar e caracterizar sintomas de desordens nutricionais.

Os efeitos dos tratamentos nas variáveis estudadas foram submetidos à análise de variância, utilizando o teste $\mathrm{F}$, a $5 \%$ de probabilidade. Para avaliar o efeito das doses de zinco, realizaram-se testes de regressão polinomial, utilizando software Estat (1997).

\section{Resultados e Discussão}

Houve incremento linear na concentração de zinco no solo, em função da aplicação do micronutriente (Figura 1). Esse resultado indica que o método utilizado para extrair o zinco no solo é adequado em função da alta correlação $\left(\mathrm{R}^{2}=0,99 * *\right)$. Pelo coeficiente angular da reta, verificou-se uma recuperação do zinco adicionado ao solo em torno de 39,7\%. Natale et al. (2004) verificaram uma recuperação de aproximadamente $50 \%$ do zinco adicionado ao solo sob o cultivo de mudas de maracujazeiro.

FIGURA 1: Concentração de zinco no solo após dois cortes do capim-Marandu, em função da aplicação do zinco. ** Significativo a $1 \%$ de probabilidade, pelo teste $\mathrm{F}$.

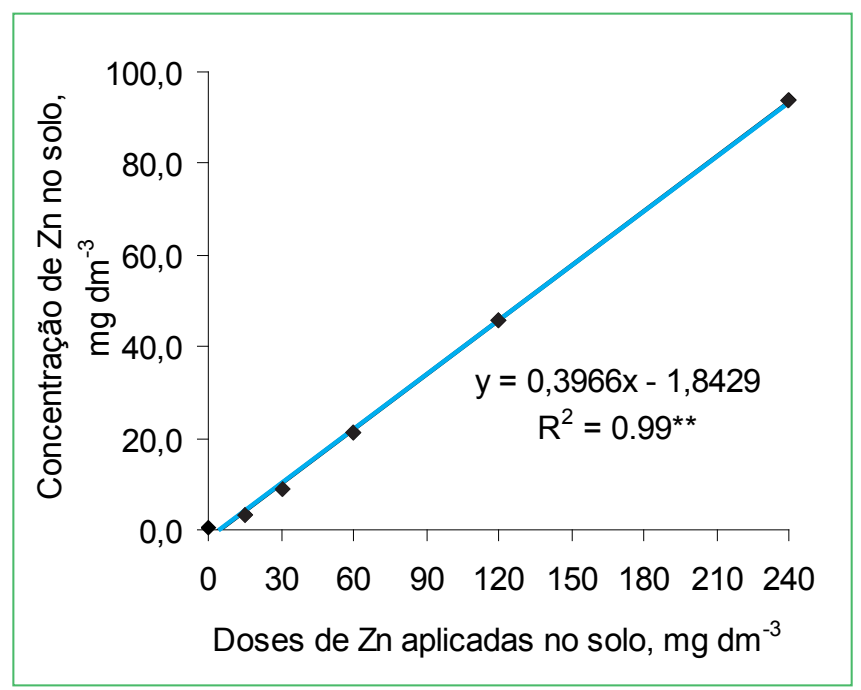

A concentração de zinco no solo variou de 0,4 a $94 \mathrm{mg} \cdot \mathrm{dm}^{-3}$, e, conforme Raij et al. (1996), esses 
valores são considerados baixo e alto, respectivamente. Hernandes et al. (2009) verificaram que a aplicação de 240mg.dm ${ }^{-3} \mathrm{Zn}$ no solo sob Capim-Tanzânia aumentou o teor de zinco no solo, cujo valor foi $120 \mathrm{mg} \cdot \mathrm{dm}^{-3}$.

A aplicação do micronutriente no solo elevou o teor (Figura 2a) e o acúmulo (Figura 2b) do zinco na parte aérea da forrageira, nos dois cortes, porém com ajuste quadrático. Assim, o aumento do zinco no solo refletiu na nutrição do capim-Marandu. O teor e o acúmulo de zinco na parte aérea do capim apresentaram correlação positiva com a concentração de zinco no solo, no primeiro corte $\left(\mathrm{r}=0,95^{* *}\right.$ e $\left.\mathrm{r}=0,94^{* *}\right)$, assim como no segundo $(\mathrm{r}=$ $0,97 * *$ e $r=0,97 * *)$, respectivamente.

FIGURA 2: Teor (a) e acúmulo de zinco (b) nas folhas do capimMarandu, em dois cortes, em função da aplicação de zinco no solo. **: Significativo a $1 \%$ de probabilidade, pelo teste $\mathrm{F}$.

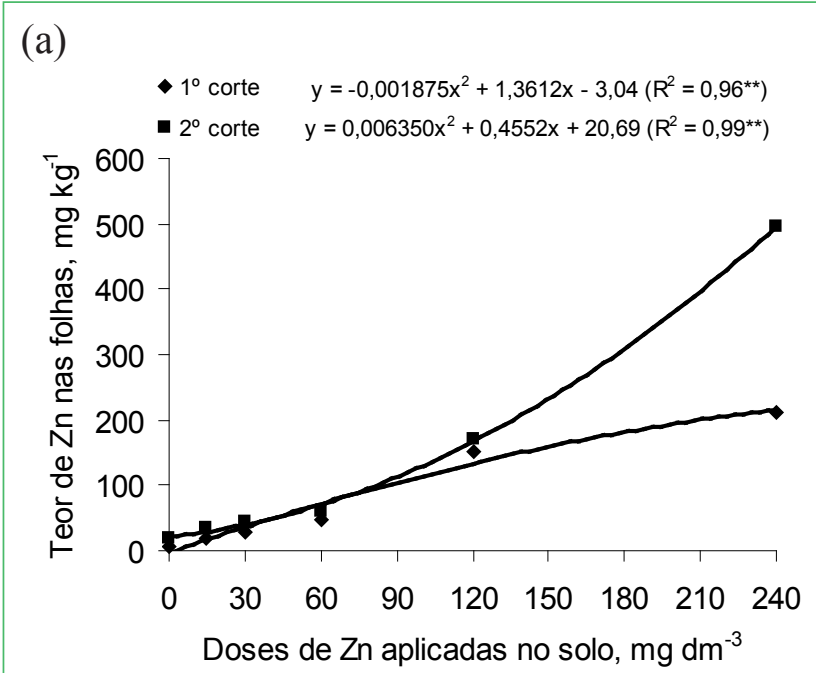

(b)

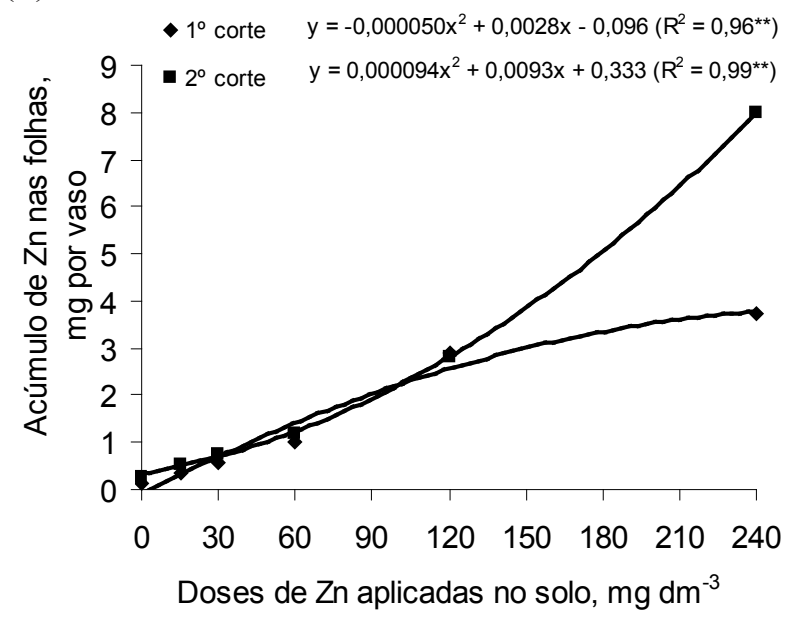

$\mathrm{Na}$ ausência de aplicação de zinco, as plantas apresentaram teores abaixo da faixa considerada adequada (20 a 50mg. $\mathrm{kg}^{-1}$ ), conforme preconizado por Werner et al. (1997), tanto no primeiro quanto no segundo cortes, apesar da ausência de sintomas visuais de deficiência deste micronutriente no tecido vegetal.

Os teores máximos de zinco na parte aérea do capim-Marandu foram de 213 e $495 \mathrm{mg} \cdot \mathrm{kg}^{-1}$, no primeiro e segundo cortes, respectivamente (Figura 2a). Não foram observados sintomas de toxicidade. Isso indica que o capim-Marandu apresenta alta tolerância à aplicação de zinco no solo, sendo maior que outras forrageiras, visto que o nível crítico de toxicidade de zinco correspondente a uma redução de $50 \%$ na produção de massa seca, para o capim-Tanzânia (HERNANDES et al., 2009), capim-Xaraés (SANTOS et al., 2009) e milheto (SILVA et al., 2010), ou seja, 273; 162-177 e $451 \mathrm{mg} \cdot \mathrm{kg}^{-1}$, respectivamente. Para aveia-preta, esse nível crítico foi de $494 \mathrm{mg} . \mathrm{kg}^{-1}$ (ABRANCHES et al., 2009), associados com diminuição de $10 \%$ na produção de massa seca da forrageira.

A aplicação de zinco não afetou o número de perfilhos, em ambos os cortes da forrageira (Figura 3a), e diminuiu com ajuste linear o número de folhas apenas no primeiro corte, embora agronomicamente pouco importante, devido ao coeficiente de determinação muito baixo $\left(\mathrm{R}^{2}=0,29\right)$ (Figura 3b).

A altura de plantas, no primeiro corte, não foi influenciada pela aplicação do zinco, enquanto, no segundo corte, houve incremento desta variável com ajuste quadrático, atingindo ponto de máximo com a aplicação de 106.mg.dm ${ }^{-3}$ de $\mathrm{Zn}$ (Figura 3c). $\mathrm{O}$ aumento na altura das plantas pode ser devido ao fato de o zinco ser componente de um grande número de enzimas, responsáveis pelo aumento do tamanho e pela multiplicação celular, e responsáveis, ainda, pelo crescimento da planta (MALAVOLTA et al., 1991).

A aplicação de zinco incrementou a produção de massa seca da parte aérea do capim-Marandu, atingindo um máximo com a aplicação de 115; 150 e 127mg.dm ${ }^{-3}$ de Zn, para o primeiro, e o segundo cortes, e para a soma dos dois cortes, respectivamente (Figura 4a). 
FIGURA 3: Efeito da aplicação de zinco no solo nas variáveis de crescimento do capim-Marandu, em dois cortes: número de perfilhos (a) e de folhas por vaso (b), e na altura de plantas (c). ${ }^{\text {ns; }}$ ** e $\mathrm{e}^{*}$ : Não significativo; significativo a 1 e $5 \%$ de probabilidade, respectivamente, pelo teste $\mathrm{F}$.

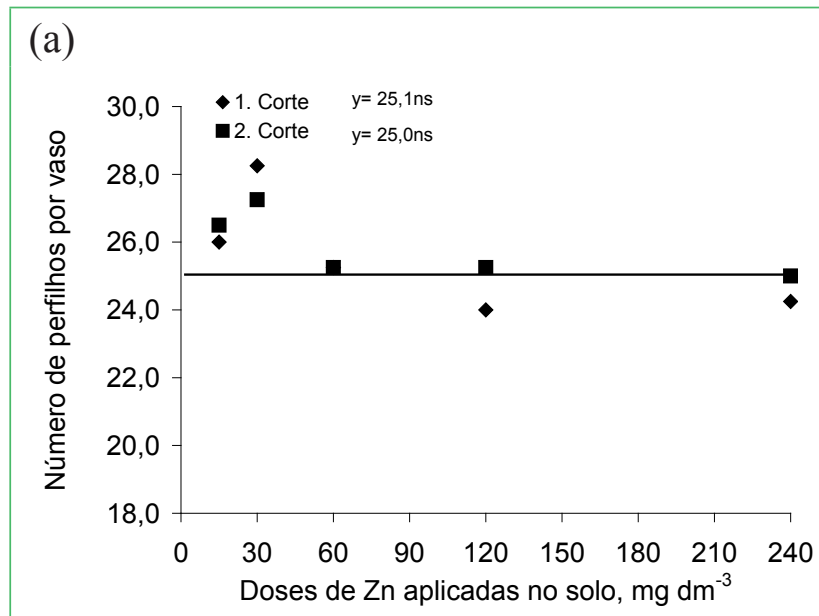

(b)

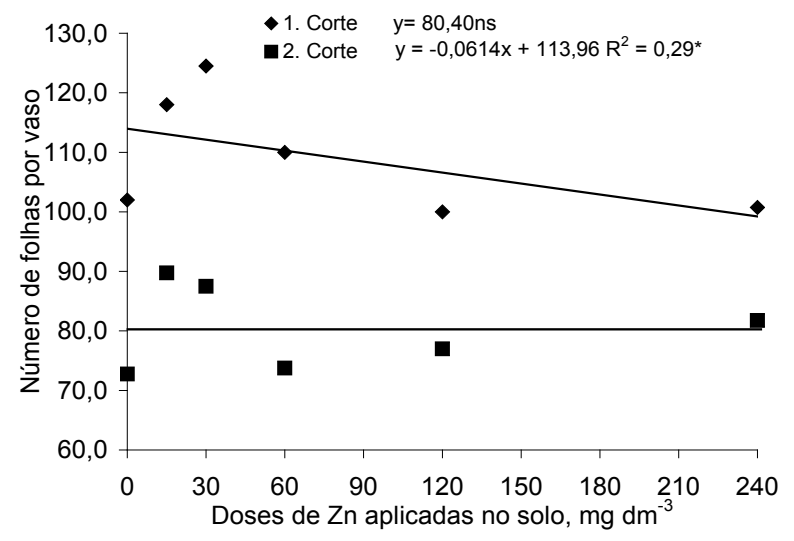

(c)

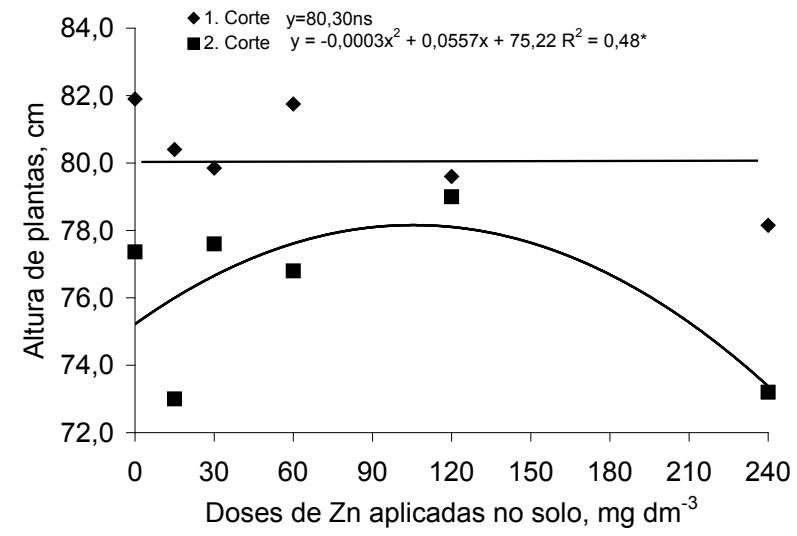

O aumento na massa seca da parte aérea do capimMarandu pode ser devido ao efeito de o zinco participar como ativador enzimático na biossíntese do triptofano, precursor do ácido indolacético. A maior concentração do ácido indolacético nas plantas é encontrada nos meristemas apicais da parte aérea, em folhas jovens em desenvolvimento; portanto, pode ser a explicação pelo aumento na massa seca da parte aérea.

Com relação à produção de massa seca de raízes, não foi verificado ajuste significativo dos modelos de regressão polinomial utilizados, em função da aplicação do micronutriente (Figura 4b).

A dose de zinco aplicada ao solo de $127 \mathrm{mg} \mathrm{dm}^{-3}$ foi a que promoveu a maior produção de massa seca (soma dos dois cortes). Essa dose correspondeu à concentração de zinco no solo, de $48 \mathrm{mg} \cdot \mathrm{dm}^{-3}$, e aos teores de zinco na parte aérea, de 140 e $181 \mathrm{mg}^{\mathrm{kg}}{ }^{-1}$, para o primeiro e segundo cortes, respectivamente.

FIGURA 4: Produção de massa seca de folhas do capimMarandu (a), em dois cortes, e de raízes (b), em função da aplicação de zinco no solo. ${ }^{\text {ns; }}$ ** e * : Não significativo; significativo a 1 e $5 \%$ de probabilidade, respectivamente, pelo teste $\mathrm{F}$.

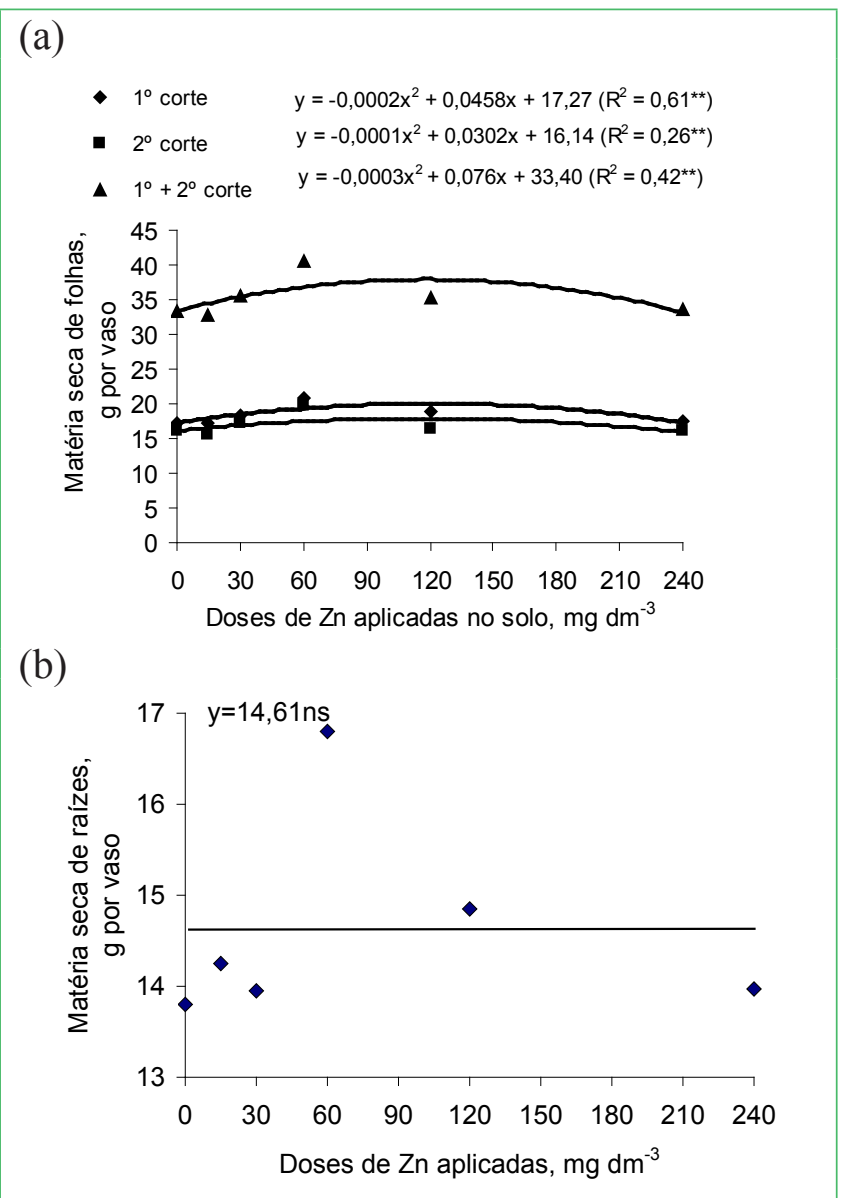


A eficiência agronômica nas doses de zinco de 15; 30; 60; 120 e 240mg.dm ${ }^{-3}$ foi de $-10 ; 25,6 ; 41,1 ; 5,9$ e $0,5 \mathrm{~g} / \mathrm{g}$. Assim, a maior eficiência agronômica foi obtida com a dose de $60 \mathrm{mg} \mathrm{dm}^{-3}$ de zinco, ou seja, a cada $1 \mathrm{~g}$ de zinco adicionado ao solo foram produzidos $41,1 \mathrm{~g}$ de massa seca do capim-Marandu. A maior eficiência agronômica ocorreu com a dose moderada de zinco.

O efeito benéfico da aplicação de zinco na produção de massa seca do capim-Marandu foi verificado no presente estudo (Figura 4a). No entanto, o efeito benéfico do zinco na produção de massa seca difere do resultado obtido por Palma (1999), pois o autor não verificou efeito na produção de massa seca da parte aérea do capimTifton 85 (soma de três cortes).

Hernandes et al. (2009) avaliaram o efeito da aplicação de zinco na produção de folhas, em dois cortes do capim-Tanzânia, e notaram efeito do nutriente apenas no primeiro corte. Os autores atribuíram a falta de resposta à aplicação de zinco devido à sua alta concentração média de zinco na testemunha, durante o primeiro corte, quando comparada com o segundo corte. No presente estudo, a concentração de zinco foi de $3,04 \mathrm{mg} \mathrm{kg}^{-1}$ no primeiro corte e $20,69 \mathrm{mg} \mathrm{kg}^{-1}$ no segundo (Figura 1a). Entretanto, a massa seca da testemunha, em ambos os cortes, foi semelhante (Figura 4a).

A aplicação de zinco ao solo incrementou sua concentração no solo e a absorção pelo capim-Marandu, atingindo a máxima produção de massa seca com teor de zinco na parte aérea de 140 e $181 \mathrm{mg}^{\mathrm{kg}} \mathrm{kg}^{-1}$, para o primeiro e segundo cortes, respectivamente. Não foi observada toxidez de zinco nas doses utilizadas.

\section{Referências}

ABRANCHES, J. L.; BATISTA, G. S.; RAMOS, S. B.; PRADO, R. M. Resposta da aveia-preta à aplicação de zinco em Latossolo Vermelho distrófico. Revista Brasileira de Ciências Agrárias, Recife, v. 4, p. 278-282, 2009.

BATAGliA, O. C.; FURLANI, A. M. C.; TEIXEIRA, J. P. F.; FURLANI, P. R.; GALLO, J. R. Métodos de análise química de plantas. Campinas: Instituto Agronômico, 1983. 48 p.

BONFIM, E. M. S.; FREIRE, F. J.; SANTOS, M. V. F. Soil and plant phosphorus critical levels for Brachiaria brizantha related to physical and chemical characteristics of soils in the State of Pernambuco, Brazil. Revista Brasileira de Ciência do Solo, Viçosa, v. 28, p. 281-288, 2004.
COSTA, K. A. P.; ROSA, B.; OLIVEIRA, I. P.; CUSTÓDIO, D. P.; SILVA, D. C. Efeito da estacionalidade na produção de massa seca e composição bromatológica da Brachiaria brizantha cv. Marandu. Ciência Animal Brasileira, Goiânia, v. 6, p. 187-193, 2005.

ESTAT. Sistema para análises estatísticas. Versão 2.0. Jaboticabal: Faculdade de Ciências Agrárias e Veterinárias, 1997. Disponível em: <http://www.fcav.unesp.br/download2/softwares/estat/>. Acesso em: 10 janeiro 2010.

EMPRESA BRASILEIRA DE PESQUISA AGROPECUÁRIA - EMBRAPA. Centro Nacional de Pesquisa de Solos. Sistema brasileiro de classificação de solos. 2. ed. Rio de Janeiro: Embrapa Solos, 2006. 306 p.

FAGERIA, N. K.; BALIGAR, V. C. Response of common bean, upland rice, corn, wheat, and soybean to soil fertility of an Oxisol. Journal of Plant Nutrition, Philadelphia, v. 20, n. 10, p. 12791289, 1997.

FAGERIA, N. K.; BARBOSA FILHO, M. P. Dry-matter and grain yield, nutrient uptake, and phosphorus use-efficiency of lowland rice as influenced by phosphorus fertilization. Communication in Soil Science and Plant Analysis, Monticello, v. 38, p. 1289-1297, 2007.

HERNANDES, A.; PRADO, R. M.; PEREIRA, F. S.; MODA, L. R.; ICHINOSE, J. G. S.; GUIMARÃES, R. C. M. Desenvolvimento e nutrição do capim-tanzânia em função da aplicação de zinco. Scientia Agraria, Curitiba, v. 10, p. 383-389, 2009.

MALAVOLTA, E.; BOARETTO, A. E.; PAULINO, V. T. Micronutrientes: uma visão geral. In: FERREIRA, M. E.; CRUZ, M. C. P. Micronutrientes na agricultura. Piracicaba: POTAFÓS, 1991. p. 1-34.

MANARIN, S. A. Combinações de doses de fósforo e de zinco em solução nutritiva para o Capim-Tanzânia. 2005. 68 f. Dissertação (Mestrado em Solos e Nutrição de Plantas) - Universidade de São Paulo, Piracicaba. 2005.

MESQUITA, E. E.; PINTO, J. C.; FURTINI NETO, A. E. Critical phosphorus concentrations in three soils for the establishment of mombaça grass, marandu grass and andropogon grass. Revista Brasileira de Zootecnia, Viçosa, v. 33, p. 290-301, 2004.

NATALE, W.; PRADO, R. M.; LEAL, R. M.; FRANCO, C.F. Efeitos da aplicação de zinco no desenvolvimento, no estado nutricional e na produção de matéria seca de mudas de maracujazeiro. Revista Brasileira de Fruticultura, Jaboticabal, v. 26, p. 310-314, 2004.

PALMA, L. A. S. Resposta de Capim-Tifton 85 à calagem e à adubação com zinco. 1999. 59 f. Monografia (Trabalho de Conclusão de Curso em Zootecnia) - Universidade Estadual Paulista, Jaboticabal. 1999.

RAIJ, B.; ANDRADE, J. C.; CANTARELLA, H.; QUAGGIO, J. A. Análise química para avaliação da fertilidade do solo. Campinas: Instituto Agronômico de Campinas, 2001. 285 p.

RAIJ, B.; CANTARELLA, H.; QUAGGIO, J. A.; FURLANI, A. M. C. Recomendações de adubação e calagem para o Estado de São Paulo. 2. ed. Campinas: Instituto Agronômico/Fundação IAC, 1996. 285 p.

SANTOS, T. M.; FARIA, A. F. G.; AVALHÃES, C. C.; PRADO, R. M. Produção de biomassa e nível crítico tóxico do capim-xaraés em função da aplicação de zinco. Boletim da Indústria Animal, Nova Odessa, v. 66, p. 53-60, 2009. 
SILVA, T. M. R.; PRADO, R. M.; VALE, D. W.; AVALHÃES, C. C.; PUGA, A. P.; FONSECA, I. M. Toxicidade do zinco em milheto cultivado em Latossolo Vermelho distrófico. Revista Brasileira de Ciências Agrárias, Recife, v. 5, p. 336-340, 2010.

SOARES FILHO, C. V.; MONTEIRO, F. A.; CORSI, M. Recuperação de pastagens degradadas de Brachiaria decumbens. 1. Efeito de diferentes tratamentos de fertilização e manejo. Pasturas Tropical, Cali, v. 14, p. 1-6, 1992.

WERNER, J. C.; PEDREIRA, J. V. S.; QUAGLIATO, J. L. Ensaio exploratório de fertilização de capim-colonião com solo de Sertãozinho. Boletim da Indústria Animal, São Paulo, v. 24, p. 155-158, 1967.

WERNER, J. C.; PAULINO, V. T.; CANTARELlA, H.; ANDRADE, N. O.; QUAGGIO, J. A. Forrageiras. In: RAIJ, B.; CANTAREllA, H.; QUAGGIO, J. A.; FURLANI, A. M. C. Recomendações de adubação e calagem para o Estado de São Paulo. 2 ed. Campinas: Instituto Agronômico, 1997. p. 263-273. 